\title{
Modal sosial sebagai sarana pembangunan ekonomi masyarakat Kelurahan Kalirejo melalui hidroponik
}

\author{
Aisyiyah Hariani, Dhanu Dewantara Aji, Lulu Chamdliyah, Rohmatin Alfisnistiawati, \\ Sanggar Sukama Sijati, Siti Hadiyatul Hasanah, Nanda Harda Pratama Meiji* \\ Universitas Negeri Malang, Jl. Semarang No. 5 Malang, Jawa Timur, Indonesia \\ *Penulis korespondensi, Surel: nanda.harda.fis@um.ac.id
}

Paper received: 01-04-2021; revised: 15-04-2021; accepted: 30-04-2021

\begin{abstract}
Various kinds of developments in various fields provide many innovations, one of which is in agriculture. The hydroponic method emerged as a new innovation in farming by utilizing soil substitute water media. Hydroponics, which are more suitable to be applied in areas with narrow land, are utilized by the villagers of Kalirejo Malang to improve the economy of the villagers. Through social capital established in the Kalirejo village community and cooperation with PT Otsuka, regional economic development is created through hydroponics. This study aims to determine how the forms of social capital that exist in the Kalirejo village community in improving the regional economy through hydroponics. The research was conducted using descriptive qualitative methods with data collection through observation and interviews. The results obtained are that there is a significant role of social capital in the management of hydroponics among residents of Kalirejo Village Malang and its relationship in improving the regional economy.
\end{abstract}

Keywords: social capital; hydroponics; economic development

\begin{abstract}
Abstrak
Berbagai macam perkembangan di berbagai bidang memberikan banyak inovasi, salah satunya di bidang pertanian. Metode Hidroponik muncul sebagai sebuah inovasi baru bercocok tanam dengan memanfaatkan media air pengganti tanah. Hidroponik yang lebih cocok diterapkan di daerah dengan lahan sempit dimanfaatkan oleh warga desa Kalirejo Malang untuk meningkatkan ekonomi warga desa. Melalui modal sosial yang terjalin di masyarakat desa Kalirejo serta kerjasama dengan pihak PT Otsuka tercipta pembangunan ekonomi daerah melalui hidroponik. Penelitian ini bertujuan untuk mengetahui bagaimana bentuk modal sosial yang terjalin di masyarakat desa Kalirejo dalam meningkatkan perekonomian daerah melalui Hidroponik. Penelitian dilakukan dengan menggunakan metode kualitatif deskriptif dengan pengumpulan data melalui observasi dan wawancara. Hasil yang diperoleh adalah terdapat peranan modal sosial yang cukup besar dalam pengelolaan Hidroponik antar warga desa Kalirejo Malang serta keterkaitanya dalam peningkatan ekonomi daerah.
\end{abstract}

Kata kunci: modal sosial; hidroponik; pembangunan ekonomi

\section{Pendahuluan}

Pada saat ini perkembangan teknologi memunculkan banyak inovasi dalam berbagai bidang. Contohnya dalam bidang pertanian dengan munculnya metode tanam hidroponik. Metode hidroponik adalah cara bercocok tanam menggunakan media air sebagai pengganti tanah. Hidroponik lebih menekankan kepada pemberian nutrisi untuk tumbuhan selain itu, jika dibandingkan dengan menggunakan media tanah hidroponik lebih efisien dalam kebutuhan air dan lahan. Hal ini menyebabkan hidroponik cocok diterapkan di daerah yang berlahan sempit dan memiliki sumber air yang tidak banyak (Ariati \& Raka, 2019). 
Kelebihan tersebut dimanfaatkan pihak PT. Otsuka Indonesia untuk memberikan sosialisasi tentang hidroponik pada warga Kalirejo. PT Otsuka sendiri adalah sebuah perusahaan gabungan Indonesia Jepang dalam bidang industri farmasi. Pt Osuka membangun pabrik cabang di Kecamatan Lawang seluas $40.000 \mathrm{~m} 2$. Sebagai tanggung jawab sosial kepada warga sekitar pabrik, PT Otsuka melaksanakan program pelatihan hidroponik (otsuka.co.id, 29 November 2019). Banyaknya lahan kosong yang sempit dan tidak dimanfaatkan oleh warga Kalirejo menjadi kriteria PT Otsuka untuk melakukan sosialisasi tentang Hidroponik. Selain sosialisasi pihak PT Otsuka juga memberikan modal fisik berupa instalasi hidroponik, bibit dan pupuk. Upaya ini dilakukan pihak Otsuka untuk mengurangi kemiskinan dan meningkatkan produktivitas warga Desa Kalirejo.

Disini peranan modal sosial sangat diperlukan agar program yang disediakan pihak Otsuka berjalan dengan baik. Menurut penelitian Cahyono (2014) menyebutkan bahwa melalui modal sosial dan pemberdayaan masyarakat dapat digunakan sebagai bentuk untuk meningkatkan kesejahteraan kelompok masyarakat dan dapat membuka lapangan pekerjaan sebagai bentuk dari pengurangan kemiskinan yang ada. Selain itu diperlukan juga berbagai program yang digagas dalam mencapai keberhasilan penembangan ekonomi masyarakat melalui modal sosial.

Modal sosial dalam masyarakat Kalirejo terdapat dalam pengelolaan tanaman hidroponik. Modal fisik yang telah diberikan PT Otsuka kepada setiap RW kemudian dikelola bersama-sama oleh warga dalam satu lingkungan warga tersebut. Terdapat pembagian tugas dalam mengelola dan merawat tanaman hidroponik yang dilakukan bersama-sama. Hal ini sejalan dengan konsep modal sosial yang didalamnya mengandung jejaring sosial, norma, solidaritas, kerjasama, dan kepercayaan untuk mencapai tujuan yang sama.

Manfaat yang didapatkan warga Kelurahan Kalirejo adalah dapat menambah pendapatan setiap masyarakat yang tergabung dalam pengelolaan hidroponik, selain itu dengan adanya hidroponik lahan sempit yang tidak dapat dimanfaatkan dapat terlihat asri dan memperindah suasana wilayah tempat tinggal.

Dalam penelitian ini bermaksud untuk mengetahui apakah dengan modal sosial dapat mengembangkan suatu wilayah yang tidak memiliki sumber daya alam yang memadai. Peneliti juga ingin mengetahui modal sosial seperti apa yang dikembangkan dalam Kelurahan Kalirejo. Selain itu apakah modal sosial selalu terwujud dalam seluruh wilayah Kelurahan Kalirejo.

\section{Metode}

Penelitian ini menggunakan metode kualitatif dengan pendekatan deskriptif untuk mengetahui data yang spesifik dan mendetail. Teknik pengumpulan data diperoleh dengan cara observasi dan wawancara di Kelurahan Kalirejo, Kecamatan Lawang, Kabupaten Malang. Wawancara dilakukan kepada warga di RW 06, 14, dan 15 dengan kriteria responden warga yang berhasil dalam menjalankan modal sosial tersebut. Peneliti juga melakukan studi literatur yang bertujuan untuk mendapatkan data yang valid sesuai dengan tema yang diteliti. Fokus dari penelitian ini adalah peneliti akan memaparkan tentang peran modal sosial dari warga yang terlibat dalam kerja sama yang dilakukan.

\section{Hasil dan Pembahasan}

Dari kegiatan penelitian yang dilakukan di Kelurahan Kalirejo, Kecamatan Lawang, Kabupaten Malang diperoleh data dari empat informan dengan RW yang berbeda. Diketahui 
bahwa kegiatan penanaman hidroponik yang ada di kelurahan Kalirejo sudah ada sejak tahun 2017 dan masih berjalan hingga saat ini. Kegiatan ini bermula dari sosialisasi PT. Otsuka Indonesia mengenai kegiatan penanaman hidroponik. Dari sosialisasi yang dilakukan oleh PT. Otsuka Indonesia. Perusahaan Otsuka kemudian memberikan modal awal berupa instalasi, pupuk, dan bibit tanaman di setiap RW. Masyarakat kelurahan Kalirejo sama sekali tidak mengeluarkan modal berupa uang. modal sosial yang dimaksud disini seperti peranan masyarakat melalui interaksi, tindakan sosial, kerja sama yang dapat membangun kepercayaan masyarakat supaya organisasi ini berjalan lancar dan sukses. tujuannya untuk meningkatkan solidaritas antar RW dan perekonomian masyarakat.

Berhasilnya dalam menjalankan modal sosial karena adanya kerja sama dan relasi antar warga. Diketahui bahwa kegiatan penanaman hidroponik dilakukan oleh ibu rumah tangga yang tidak memiliki pekerjaan dan penghasilan. Banyak ibu rumah tangga di RW 15, 14, 6 yang menekuni kegiatan ini dan menjadikannya pekerjaan tetap. Dari penghasilan yang diperoleh setiap bulannya bisa meningkatkan perekonomian dalam keluarga. Kegiatan penanaman hidroponik di RW 06, 14, dan 15 ini diperoleh modal sosial yang berjalan dengan baik, karena hampir semua ibu rumah tangga ikut berpartisipasi dalam kegiatan. Di RW tersebut mereka bekerja sama dalam satu khusus hidroponik dengan instalasi 15 yang dapat dikerjakan bersama-sama.

Modal sosial yang dibangun dalam budidaya tanaman hidroponik di setiap RW pasti melakukan pembagian tugas dalam melakukan perawatan tanaman. Pembagian tugas tersebut diberikan kepada warga yang memiliki kemauan untuk bergabung dalam mengembangkan tanaman hidroponik di setiap RW. Pembagian tugas tersebut seperti menyemai bibit, membersihkan instalasi, pengecekkan kadar air, pemberian nutrisi, dan ketika panen melakukan panen bersama. Pembagian tugas tersebut dilakukan agar kegiatan menjadi efisien karena hasilnya nanti dinikmati bersama.

Dalam setiap tugas tidak hanya dikerjakan oleh satu orang saja melainkan dalam satu pembagian tugas dilakukan oleh dua sampai tiga orang. Hal tersebut dimaksudkan untuk tetap adanya kerja sama walaupun terdapat pembagian tugas. Menjalin interaksi antar warga juga diperlukan dalam melakukan kegiatan yang dilakukan. Setiap pembagian tugas yang diterima harus dikerjakan dengan tanggung jawab.

Modal sosial yang terbentuk dari kesamaan wilayah dan adanya tujuan yang ingin dicapai bersama. Jadi warga dalam setiap RW melakukan budidaya hidroponik secara bersama-sama. Modal sosial juga terbentuk jaringan antar RW ketika satu wilayah RW akan mendapatkan pesanan sayur para petani setiap RW akan saling memberi kabar bahwa di RW ini mempunyai stok sayur yang banyak. Jadi kerjasama yang ada tidak hanya di lingkungan setiap RW melainkan dalam satu kelurahan juga terjadi kerjasama.

Dalam melakukan kerja sama akan muncul dengan sendirinya jiwa solidaritas menurut informan yang kami wawancara. Hal tersebut dilihat dari jika saat panen setelah melakukan panen bersama para warga selalu melakukan evaluasi dalam penanaman. Evaluasi kinerja warga juga dibahas untuk memperbaiki hasil yang sebelumnya. Solidaritas yang dimaksud tidak saling menyalahkan pekerjaan setiap warga tetapi saling memperbaiki kekurangan yang ada. Seperti jika ada warga yang memberi pupuk tidak tepat waktu maka warga yang lain dengan kesadaran warga yang mengetahui memberi pupuk, dan tidak menyalahkan orang yang mendapatkan tugas memberi pupuk. 


\subsection{Bentuk-Bentuk Modal Sosial dalam Pengembangan Hidroponik}

Dalam upaya pengembangan hidroponik peranan modal sosial sangat diperlukan agar dapat berjalan dengan baik. Modal sosial ini dapat dilihat dari kerjasama yang dilakukan masyarakat Kalirejo dalam bentuk pembagian tugas dalam melakukan perawatan tanaman hidroponik. Kerjasama yang dijalin atas dasar kedekatan wilayah dan untuk mencapai tujuan yaitu membangun taman hidroponik di wilayah RW nya. Pembagian tugas tersebut seperti menyemai bibit, pemberian pupuk, Pemindahan dari semaian ke instalasi. Pembagian tugas tersebut dimaksudkan untuk mempermudah perawatan jadi beban yang ada di tanggung bersama. Jaringan yang ada terdapat di setiap RW karena ketika terdapat RW yang mendapatkan kunjungan dari sekolah atau pesanan dari sebuah perusahaan yang banyak dan membutuhkan jumlah sayur yang banyak maka setiap RW akan membantu dalam mencukupi kekurangan sayur tersebut, selain itu anggota RW lain juga berperan dalam menjamu tamu kunjungan tersebut. Kerja sama yang dilakukan oleh masyarakat Kalirejo semakin mengeratkan hubungan antar warga.

Beberapa bentuk modal sosial yang ada dalam pengembangan hidroponik warga Kalirejo antara lain: (1) Partisipasi dalam suatu jaringan yang digambarkan melalui keikutsertaan warga kelurahan Kalirejo terutama ibu rumah tangga dalam pengembangan hidroponik. Peran ibu rumah tangga ini sangat berpengaruh terhadap keberhasilan hidroponik. Hal itu dapat dilihat dari peran ibu rumah tangga sebagai penanggung jawab dalam setiap kegiatan. Kegiatan tersebut seperti pembagian tugas yang diberikan kepada anggota, memberikan pendampingan dalam perawatan, dan memasarkan hasil panen kepada khalayak umum. (2) Kepercayaan antar warga Kelurahan Kalirejo didapatkan dari pembagian tugas yang diberikan kepada setiap anggota yang dikerjakan secara tanggung jawab, sehingga kepercayaan antar warga terjalin dengan baik. Dalam pembagian hasil panen juga terdapat kepercayaan karena setiap anggota mendapatkan uang hasil panen secara merata sesuai dengan tugas yang dikerjakan. (3) Norma yang harus dipatuhi dan dijalankan oleh warga Kalirejo dengan mengerjakan pembagian tugas yang diberikan sesuai dengan waktu yang telah disepakati bersama. Pembagian uang hasil panen dibagi secara merata tidak ada warga yang keberatan dengan yang didapat. Karena setiap tugas yang diberikan sudah terdapat perhitungan sesuai dengan hasil yang akan didapat. (4) Dalam pembagian tugas juga terdapat toleransi yang ada dalam kegiatan. Ketika terdapat anggota yang lupa melaksanakan tugas yang diberikan warga lain yang mengetahui mengerjakan apa yang belum dikerjakan. Setelah itu salah satu warga akan memberikan teguran untuk melakukan tugas yang diberikan. (5) Solidaritas antar warga terlihat dari kegiatan perawatan yang dilakukan secara bersama. Dalam proses panen semua warga turut berperan dalam memanen hasil sayur hidroponik. Tidak ada yang merasa terbebani dengan pembagian tugas yang diberikan. (6) Setiap warga memiliki tanggung jawab sendiri dalam menjalankan tugasnya sesuai dengan pembagian yang sudah disepakati bersama. Jika setiap warga menjalankan tanggung jawab secara sungguhsungguh maka modal sosial akan terjalin semakin kuat.

\subsection{Keterkaitan Modal Sosial dengan Pengembangan Ekonomi Daerah}

Dalam rangka pembangunan ekonomi Daerah diperlukan kerja sama antara masyarakat dan instansi pemerintah atau instansi swasta. Hal tersebut terlihat dari kerjasama antara masyarakat kalirejo dengan PT. Otsuka Indonesia. Kerja sama yang terjadi antara keduanya berupa pemberian modal usaha kepada warga desa Kalirejo untuk pengembangan hidroponik. 
Hal ini dilakukan pihak PT Otsuka memberikan tanggung jawab warga sekitar pabrik. Selain itu program ini digunakan untuk meningkatkan produktivitas warga Desa dan mengentaskan kemiskinan.

Adanya program ini bertujuan untuk mengurangi jumlah pengangguran dan memperbaiki kondisi ekonomi masyarakat kalirejo. Kondisi perekonomian masyarakat Kalirejo sebelumnya banyak yang tidak memiliki pekerjaan dan berkemampuan ekonomi yang rendah. Setelah program budidaya hidroponik ini berjalan mampu mengubah kondisi perekonomian masyarakat Kalirejo.

Dampak dari adanya pengembangan hidroponik tidak hanya pada sektor perekonomian saja, tetapi juga pada sektor lingkungan. Hal tersebut terlihat dari tampilan instalasi hidroponik yang unik dan menarik, saat tanaman sudah tumbuh besar memberikan kesan yang indah dan asri. Dampaknya adalah masyarakat kelurahan Kalirejo sering didatangi sebagai tempat kunjungan wisata edukasi. Hal ini mengubah pandangan masyarakat yang sebelumnya menganggap Kelurahan Kalirejo terlalu banyak pabrik dan memiliki sumber daya yang tidak dapat dimanfaatkan.

\subsection{Pemberdayaan Masyarakat}

Adanya program budidaya dengan cara Hidroponik telah mampu memberdayakan masyarakat Kelurahan Kalirejo karena sebelumnya banyak warga yang tidak mempunyai pekerjaan terutama ibu rumah tangga. Diharapkan ibu rumah tangga bisa memiliki kegiatan positif dan menghasilkan pendapatan lebih. Pendapatan ini kemudian dapat membantu menambah penghasilan keluarga sehingga masyarakat yang ada bisa hidup dengan makmur dan mengurangi angka kemiskinan di daerahnya. Selain itu banyak ibu rumah tangga yang berminat untuk ikut dalam melakukan budidaya sayur dengan cara hidroponik, karena cara perawatannya mudah dan memiliki nilai jual tinggi dibandingkan dengan sayuran yang ditanam dengan media tanah. Hasil panen yang diperoleh dapat menambah perekonomian keluarga yang dilakukan oleh para ibu rumah tangga. Budidaya tanaman hidroponik ini juga dapat digunakan sebagai pekerjaan tetap karena hasil panen yang diperoleh pasti laku dijual karena sudah terdapat pengepul yang menerima. Harga pasaran tanaman hidroponik juga lebih tinggi dan proses penanamannya tidak dipengaruhi oleh musim.

Penanaman hidroponik yang dilakukan masyarakat Kalirejo ini berkaitan dengan konsep modal sosial. Modal sosial yang dimaksud adalah suatu kegiatan kerjasama yang terbangun karena adanya ikatan untuk mencapai tujuan bersama. Tujuan dari pihak Otsuka adalah untuk membantu memberdayakan dan meningkatkan penghasilan masyarakat agar tercipta kehidupan yang makmur. Masyarakat Kalirejo sendiri menerima dan menerapkan apa yang telah disosialisasikan oleh pihak Otsuka karena adanya tujuan untuk memperbaiki keadaan ekonomi. Dari sini dapat dikatakan bahwa pihak Otsuka maupun masyarakat memiliki tujuan yang sama yaitu meningkatkan perekonomian.

Berdasarkan penelitian yang telah dilakukan diperoleh hasil bahwa modal sosial memiliki peranan yang besar dalam peningkatan ekonomi masyarakat desa Kalirejo Malang. Dimana modal sosial yang terbentuk antar warga desa meliputi terciptanya jaringan relasi yang kuat antara warga desa dengan pihak PT Otsuka sebagai pemberi modal sebagai bentuk tanggung jawab pihak PT terhadap warga desa. Selanjutnya modal sosial yang terbentuk juga dapat dilihat dari peranan, tanggung jawab, serta solidaritas warga desa dalam pengelolaan 
hidroponik yang ada. Penemuan ini berbeda dengan penelitian yang telah dilakukan oleh Witjaksono dengan menggunakan perspektif ASPILOW. Dimana dengan penerapan perspektif ASPILOW ditemukan bahwa modal sosial dinilai sebagai pilar dari modal sosial lain seperti modal fisik, finansial, dan manusia. Penelitian tersebut juga menyebutkan bahwa dalam pengembangan sentra industri logam Waru Sidoarjo modal sosial berperan penting dalam lima fase yaitu perintisan, sentra pande besi, sentra industri logam (SILOW), SILOW-Sinergi I dan SILOW-Sinergi II.

Pada dasarnya kelompok penanaman hidroponik warga desa Kalirejo lebih kepada pemberdayaan masyarakat, terutama kalangan ibu rumah tangga. Dimana pemberdayaan ini dilakukan dengan asas modal sosial guna mencapai target yang telah dibuat, yaitu pembangunan ekonomi daerah. Melalui modal sosial yang terbentuk secara bersama masyarakat warga desa Kalirejo mampu meningkatkan perekonomiannya melalui hidroponik disamping pekerjaan tetapnya. Program ini juga merupakan bentuk dari tanggung jawab PT Otsuka terhadap warga desa atas berdirinya pabrik mereka.

\section{Simpulan}

Dari penelitian ini dapat ditarik kesimpulan bahwa modal sosial memiliki peranan yang penting dalam pengembangan ekonomi masyarakat. Melalui modal sosial ini masyarakat dapat bekerja sama dan membangun sebuah relasi untuk meningkatkan perekonomian. Modal sosial ini akan berjalan dengan baik bila terdapat kerjasama dan rasa saling percaya antar warga. Selain itu adanya pembagian tugas dan peran yang diberikan kepada masing-masing warga dapat menambah kekuatan modal sosial. Sehingga pengembangan ekonomi daerah Kalirejo semakin meningkat dengan adanya modal sosial yang baik.

\section{Daftar Rujukan}

Afriliansyah, B., \& Sugihen, B. T. (2019). ANALISA MODAL SOSIAL PADA KELOMPOK TANI (Studi Pada Kelompok Tani di Kecamatan Bukit, Kabupaten Bener Meriah). Jurnal Ilmiah Mahasiswa Fakultas Ilmu Sosial \& Ilmu Politik, 4(1).

Ariati, P. E. P., \& Raka, I. D. N. (2019). Sosialisasi Hidroponik Sebagai Basis Peningkatan Perekonomian Masyarakat Merupakan Pendongkrak Nilai Tambah Pendapatan Keluarga. Agrimeta: Jurnal Pertanian Berbasis Keseimbangan Ekosistem, 9(17), 53-57.

Arsyad, L. (1999). Pengantar perencanaan dan pembangunan ekonomi daerah. Badan Penerbitan Fakultas Ekonomi (BPFE).

Cahyono, B. (2014). Peran modal sosial dalam peningkatan kesejahteraan masyarakat petani tembakau di kabupaten wonosobo. Jurnal Ekonomi dan Bisnis, 15(1), 1-16.

Handayani, N. (2007). Modal Sosial dan Keberlangsungan Usaha (Studi Deskriptif Kualitatif tentang Keterkaitan Hubungan Modal Sosial dengan Keberlangsungan usaha Pengusaha Batik di Kampung Kauffman, Kelurahan Kauffman, Kecamatan Pasar Kliwon, Surakarta). Surakarta: Universitas Sebelas Maret.

Mustanir, A. (2019). Pemberdayaan masyarakat kewirausahaan.

Nakuloadi, H. (2019). Pengembangan hidroponik sebagai sarana hulu kemandirian pangan berbasis pemberdayaan ekonomi di Kampung Pugeran Kelurahan Suryodiningratan Kecamatan Mantrijeron, Kota Yogyakarta. Prima Ekonomika, 10(1), 1-20.

Sukirno, S. (2000). Ekonomi Pembangunan Proses, Masalah dan Dasar Kebijakan Pembangunan. UI-Press. Jakarta.

Sumodiningrat, G. (1997). Pembangunan daerah dan pemberdayaan masyarakat. Jakarta: Bina Rena Pariwara. Sumodiningrat, G. (1999). Pemberdayaan masyarakat dan jaring pengaman sosial. Gramedia Pustaka Utama.

Syahra, R. (2003). Modal sosial: Konsep dan aplikasi. Jurnal Masyarakat dan Budaya, 5(1), 1-22.

Yuliarmi, N. N. (2011). Peran modal sosial dalam pemberdayaan industri kerajinan di Provinsi Bali. PIRAMIDA. 
Jurnal Integrasi dan Harmoni Inovatif Ilmu-Ilmu Sosial, 1(4), 2021, 510-516

Witjaksono, M. (2015). Modal sosial dalam dinamika perkembangan sentra industri logam Waru Sidoarjo. Jurnal Ekonomi Pembangunan: Kajian Masalah Ekonomi dan Pembangunan, 11(2), 266-291. 